\title{
Asexual reproduction and genetic determination of colour patterns within populations of the subtidal sea anemone Anthothoe albocincta
}

\author{
Martin R. Billingham*, David J. Ayre \\ Department of Biological Sciences and Australian Flora and Fauna Research Centre, University of Wollongong, \\ Wollongong, New South Wales 2522, Australia
}

\begin{abstract}
Southeastern Australian populations of the dioecious, subtidal sea anemone Anthothoe albocincta display considerable spatial variation in the colour patterns of the constituent polyps, and the most visually striking feature of local populations are sets of dense aggregations each comprised of polyps with a single colour pattern. We used a combination of genetic data, observations and manipulative experiments to infer that $A$. albocincta generates these monomorphic aggregations via asexual reproduction and that asexual reproduction plays the major role in the maintenance of established populations. Allozyme electrophoresis of 2 to 5 polyps from each of 20 mapped aggregations (in 2 populations) revealed that in 18 cases $(90 \%)$ all polyps were electrophoretically identical and always distinct from differently coloured polyps taken from each of 26 adjacent aggregations. Furthermore, the genetic structure of each of 13 populations separated by up $10930 \mathrm{~km}$ was consistent with the predicted effects of localised asexual recruitment. We detected 16 heterozygote excesses and 11 heterozygote deficits $(p<0.05)$ in a total of 66 tests for departures from Hardy-Weinberg equilibria. Moreover, each population contained significantly less $(p<0.005)$ multi-locus genotypic diversity $\left(G_{0}\right)$ than was expected for a randomly mating population $\left(G_{e}\right)$ (mean $G_{0}: G_{e}=0.30$ ) and contained relatively few unique 7 -locus genotypes. Some genotypes were found within many aggregations, suggesting successful clones may have extensive and discontinuous distributions within populations. In addition, we observed longitudinal fission of adult polyps in both field and laboratory conditions, and found that over a 6 mo period $82 \%$ (i.e. 1469 of 1790) of new recruits into 30 experimentally cleared patches, within 3 populations, were morphologically identical to those within surrounding aggregations. These data, together with our earlier analysis of genetic vanation among populations, and observations of gonad development, imply that this species uses fission to maintain populations, consisting predominantly of spatially restricted clones (each with an almost unique colour pattern), but uses sexual reproduction to produce widely dispersed colonists
\end{abstract}

KEY WORDS: Cnidarian · Asexual - Sexual · Colour morph · Longitudinal fission

\section{INTRODUCTION}

Despite the potential of marine organisms for dispersal over vast spatial scales, recent studies have found that populations of many marine organisms are highly genetically subdivided (e.g. Ayre 1983, 1984, Johnson \& Black 1984a, 1991, Burton 1986, 1990, Hoffmann

\footnotetext{
- Present address: Department of Plant Sciences, University of Oxford, South Parks Road, Oxford OX1 3RB, United Kingdom.E-mail:martin.billingham@plant-sciences.oxford.ac.uk
}

1986, Grosberg 1987, 1991, Ayre \& Dufty 1994). In many of these cases the proximate cause of subdivision has been inferred to be the philopatric dispersal of gametes and/or sexually or asexually produced propagules. However, there is increasing evidence that subdivision may also be reinforced by, as yet poorly studied, fine-scale genotype by environment interactions (e.g. Johnson \& Black 1984b, Ayre 1985 1995, Behrens Yamada 1989, Johannesson et al. 1990) and barriers to gene flow produced by the formation of co-adapted gene complexes (e.g. Burton 1986, 1990 Grosberg 1987, 1991). 
In sea anemones sexual reproduction may involve one of many tactics including self-fertilisation and external brooding of larvae (e.g Epiactis prolifera; Bucklin et al. 1984), philopatric dispersal of outcrossed larvae (e.g. Diadumene leucolena; Shick \& Lamb 1977) or outcrossed, broadcast spawning (e.g Oulactis muscosa; Hunt \& Ayre 1989) and so have the capacity to either create or overwhelm genetic structuring within populations. Asexual reproduction may occur via processes ranging from fission to parthenogenetic production of larvae (reviewed by Shick 1991), and, in the intertidal, asexual reproduction is usually associated with spatially restricted clonal proliferation leading to highly structured 'clonal' populations (e.g. Shick et al. 1979, Ayre 1983, Shaw 1991, McFadden et al. 1997). The philopatric dispersal of either sexually or asexually generated propagules provides the proximate cause of fine-scale (within population) and meso-scale (within region) genetic subdivision within at least several sea anemone species (reviewed by Shick 1991). Nevertheless, our understanding of the ecological or evolutionary significance of fine-scale genetic structure within local populations of most species remains uncertain and experimental studies are seriously impeded by the need to identify individual genotypes. Such identification typically requires the time consuming assessment of variation in protein or nucleic acid markers.

Local populations of the dioecious, subtidal sea anemone Anthothoe albocincta (Stuckey) (Tribe Mesomyaria, Family Sagartiidae) are characterised by striking spatial variation in the colours of the oral discs and tentacles of their constituent polyps (Carlgren 1950, 1954, Thomas \& Shepherd 1982, Billingham \& Ayre 1996). A. albocincta is common along the shores of southeastern Australia, forming large populations (some with 1000 s of polyps). Populations extend across a wide vertical range $(0$ to $>24 \mathrm{~m})$ and occur on many substrates (most commonly rock, but also sponges, algae, gastropod shells and ascidians; Billingham pers. obs.). Numerous different colour morphs exist within most populations, although most polyps are found within dense aggregations of identically coloured individuals, which are themselves in. close proximity to other aggregations (Billingham \& Ayre pers. obs.).

Asexual replication of identically coloured polyps would provide the simplest explanation of the colour variation seen within populations of Anthothoe albocincta. Qualitatively similar interclonal variation has been reported for the fissiparous, North American intertidal anemone Anthopleura elegantissima (Francis 1973, Ayre \& Grosberg 1995). Alternative explanations for the presence of monomorphic aggregations of polyps within populations of $A$. albocincta include the possibility that either: (1) colour is genetically determined and aggregations are produced by the philopatric dispersal of sexually generated but closely related individuals or (2) colour varies simply in response to underlying patterns of environmental variation (phenotypic plasticity). Each alternative explanation would be distinguished by a different pattern of genotypic structuring within populations.

If each monomorphic aggregation consists of a single clone then individual polyps within each aggregation should share the same multilocus genotype and be genetically different to dissimilarly coloured neighbouring anemones. Single-locus genotype frequencies within such 'clonal' populations should differ from expectations for Hardy-Weinberg equilibria, with both excesses and deficits of heterozygotes present (e.g. Ayre 1983). Alternatively, if the limited dispersal of sexually derived progeny gives rise to aggregations then individuals within aggregations would be expected to be genetically similar (though not identical) and fine-scale population subdivision should result in lower than expected numbers of heterozygotes (i.e. Wahlund effect; Hedrick 1985). Finally, if colour has no simple genetic basis but reflects a phenotypically plastic response to fine-scale environmental heterogeneity then any genotypic and phenotypic variation should vary independently.

In this study we used allozyme electrophoresis together with field and laboratory observations, and experimental manipulations to show that: (1) within 2 populations single colour aggregations of Anthothoe albocincta result from asexual reproduction via longitudinal fission; (2) successful clones may have extensive and discontinuous distributions within populations; and (3) asexually derived recruitment plays the major role in maintaining each of 13 populations of $A$. albocincta over $930 \mathrm{~km}$ of coastline.

\section{METHODS}

Collection and electrophoresis. We collected anemones from between 4 and $10 \mathrm{~m}$ depth by prising them from the substrata using a small knife. We then transported them live to the laboratory in individual plastic bags $1 / 3$ filled with cool sea water and stored them at $-80^{\circ} \mathrm{C}$ pending electrophoresis. We used horizontal starch gel electrophoresis (12.5\% w/v starch) as described in Billingham \& Ayre (1996) to determine a multilocus genotype for each sampled polyp of Anthothoe albocincta. We assessed the variation at each of 7 variable enzyme-encoding loci, using the electrophoretic buffers and assay conditions described by Selander et al. (1971) - on buffer number 5: glutamate dehydrogenase (GDH; E.C. 1.4.1.3), 6-phospho- 
gluconate dehydrogenase (6PGD; E.C.1.1.1.44) and xanthine dehydrogenase $(\mathrm{XDH})$; on buffer number 6 : leucine-alanine peptidase (PEP- C $;$ E.C. 3.4.11); and on buffer number 9: glucosephosphate isomerase (GPI; E.C. 5.3.1.9), isocitrate dehydrogenase (IDH; E.C. 1.1.1.42) and phosphoglucomutase (PGM; E.C. 2.7.5.1). All enzymes were apparently monomeric or dimeric (except for GDH which has a higher order multi-subunit structured; Catmull et al. 1987), and isozyme patterns were similar to those described for other species with Mendelian inheritance. At each locus alleles were labelled alphabetically in order of decreasing electrophoretic mobility.

Genotypic diversity within aggregations. In order to use allozyme variation to assess the importance of asexual recruitment in the formation of aggregations of Anthothoe albocincta, we first surveyed the 7-locus genotypes of single polyps taken from each of 28 randomly chosen aggregations, representing 13 different colour morphs, on a $23 \mathrm{~m}$ length of subtidal rock wall (approximately $100 \mathrm{~m}^{2}$ ) at Flagstaff Hill (Fig. 1). This survey provided an estimate of the level of allelic variation within the population and

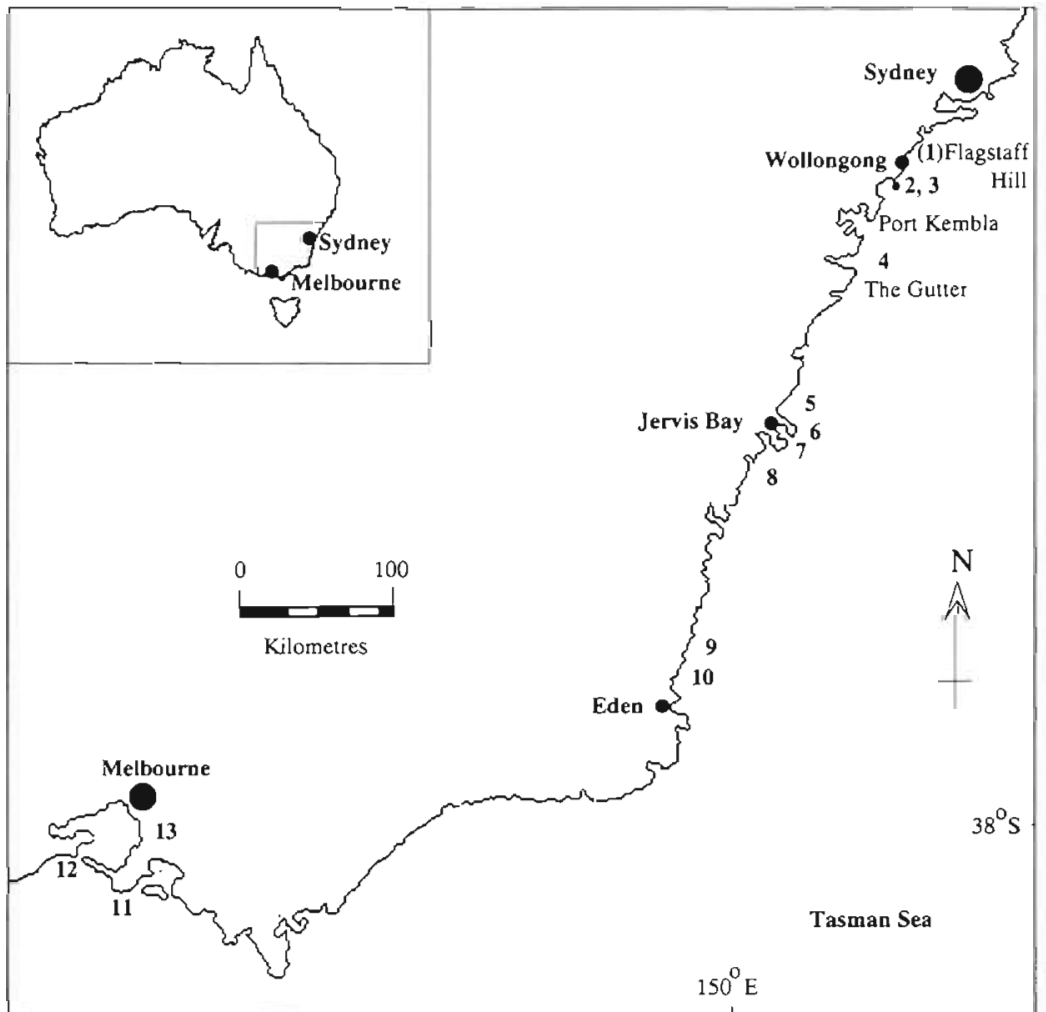

Fig. 1 Southeastern coastline of Australia, showing the study populations; all numbered populations were used for electrophoretic comparisons. The Flagstaff Hill, Port Kembla and Gutter populations were also used in a recruitment study. Other numbered populations: 2, Toothbrush Island (north); 3, Toothbrush lsland (south); 4, Gravel Loader; 5, Turtle Row; 6. Bowen Island; 7, Governor's Head; 8, Ulladulla; 9, Tathra; 10, Merimbula; 11. Flinders; 12, Queenscliff; 13, Mornington allowed us to identify 10 aggregations

in which the sampled polyp was heterozygous for 2 or more loci. In order to test for evidence of asexual replication within aggregations we then assayed an additional 4 polyps within each of the 10 potentially 'heterozygous' aggregations, as well as 3 to 5 differently coloured polyps from areas adjacent to 6 of these aggregations. The remaining 4 'heterozygous' aggregations were themselves neighbours and polyps within 2 of these displayed subtle colour variation. If these aggregations of identically or similarly coloured anemones were generated by asexual reproduction then for all loci at which the first polyp taken from a given aggregation was heterozygous all 5 polyps should be identically heterozygous, whereas aggregations generated by sexual reproduction may be genotypically diverse. Moreover, if colour is genetically determined then adjacent polyps with different colours should be genetically distinct and may display detectably different electrophoretic phenotypes. In addition we tested for asexual replication of genotypes within aggregations by determining the genotypes of 2 polyps/aggregation from each of 12 aggre- gations, representing 10 differently coloured aggregations, on the wooden pier pilings and rubble below the Mornington Jetty (Fig. 1).

Genotypic diversity within populations. In order to test for geographic variation in the relative importance of sexual and asexual recruitment in maintaining entire populations we collected Anthothoe albocincta from each of 13 southeastern Australian sites along $930 \mathrm{~km}$ of coastline (Fig 1). In most cases we collected a single polyp from each of 15 to 62 randomly selected aggregations within areas of 50 to $700 \mathrm{~m}^{2}$. However, at Tathra and Merimbula (Fig. 1) we collected relatively few anemones over the smaller areas of 25 and $5 \mathrm{~m}^{2}$, respectively, as no other anemones could be located at sites inspected in this region. For the northern populations (Flagstaff Hill to Ulladulla; Fig. 1) we sampled anemones from rock walls and boulders. Collections within the 5 southern populations (Tathra to Mornington; Fig. 1) were made from pilings and/or rubble beneath jetties.

Analysis of the genotypic structure of populations. Wright's (1978) fixation index $(f)$ was used to describe 
the magnitude of departures from the level of heterozygosity expected under Hardy-Weinberg equilibria Positive values of $f$ reflect a deficit of heterozygotes whilst negative values indicate an excess of heterozygotes. We assessed the statistical significance of such departures using chi-square tests to compare the observed and expected proportions of homozygous and heterozygous individuals within each population.

We used 2 analyses to further estimate the effect of asexual reproduction on the genotypic structure of populations and to compare clonal richness and diversity across populations. Firstly, we calculated the observed level of clonal diversity, i.e. the number of unique multilocus genotypes detected in the population $\left(N_{\mathrm{g}}\right)$, divided by the sample size $(N)$ (Hoffmann 1986). As only a small fraction of the genome was sampled electrophoretically, each unique 7 -locus genotype may represent more than 1 clone. $N_{\mathrm{q}} / N$ may therefore underestimate the true clonal diversity. Consequently we used the method of Hoffmann (1986) in order to infer whether we had detected all possible clones within each collection, i.e. the number of unique multilocus genotypes was determined firstly using only each individual polymorphic locus, then all possible 2 polymorphic locus combinations, all possible 3 polymorphic locus combinations and so on until all loci were included. The average number of multilocus genotypes identified for all 1 locus, 2 loci combinations, etc., was then calculated. If all clones were recognized, a plot of number of polymorphic loci included versus average number of multilocus genotypes detected should reach an asymptote that indicates the actual number of clones sampled.

Second, we estimated the effect of asexual recruitment on the genotypic composition of populations by comparing the observed level of 7 -locus genotypic diversity $\left(G_{0}\right)$ to that of the expected $\left(G_{\mathrm{e}}\right)$ under conditions of sexual reproduction and free recombination for a population with the sample allele frequency and size (Stoddart \& Taylor 1988). Deviations of $G_{0}: G_{e}$ from unity provide a measure of the effects of departures from single locus Hardy-Weinberg equilibria and multilocus linkage equilibria. Populations with high levels of asexual input should exhibit relatively low $G_{0}: G_{e}$. We evaluated differences between $G_{0}$ and $G_{e}$ for each population using an unpaired t-test (Stoddart \& Taylor 1.988).

Recruitment into cleared quadrats. Since the colour of recruits may provide an indication of their source and mode of production we examined recruitment into experimentally cleared quadrats at the Flagstaff Hill, Port Kembla and Gutter sites (Fig. 1) between January and June, 1993. In each population we cleared 10 quadrats $(15 \times 15 \mathrm{~cm})$ within an area containing 1 or 2 colour morphs. We subsequently monitored recruit- ment into these quadrats on a monthly basis (weather permitting) recording numbers and colour of all anemones present. All quadrats were in areas densely populated with Anthothoe albocincta and were a minimum of $10 \mathrm{~cm}$ from surrounding colour morphs. When the quadrats were cleared, we recorded the colour of anemones removed.

We used the total numbers of original and non-original coloured polyps present to determine percentage of original polyps present. We also used repeated measures ANOVAs (Glantz \& Slinter 1990) within populations to test whether there was temporal variation in recruitment of non-original colour morphs within each site. The number of non-original colour morphs present was not the same as the number of polyps (e.g. if 3 green oral disc/orange tentacles and 2 brown oral disc/white tentacles anemones were found in a quadrat, with both colour morphs being non-original, then we assessed the number of new colour morphs present as 2).

Laboratory observations of asexual reproduction. In order to observe the reproduction of Anthothoe albocincta directly, we collected 18 individuals from the Flagstaff Fill (Fig. 1) site in September 1992 and observed their development for $16 \mathrm{wk}$. We kept each anemone in separate $1 \mathrm{l}$ aquaria for $16 \mathrm{wk}$ and fed them with Artemia sp. approximately weekly. We replaced the sea water once or twice weekly. We monitored the relative size, change in number, and condition of anemones present in each container.

\section{RESULTS}

\section{Genotypic diversity within aggregations}

Our data show that aggregations of Anthothoe albocincta typically consist of genotypically identical groups of putative clones. At Flagstaff Hill we found no genotypic variation within each of the groups of 5 polyps taken from 7 of the 8 uniformly coloured aggregations (aggregations A to $\mathrm{H}$; Table 1). We detected 3 multilocus genotypes within aggregation $\mathrm{D}$, howcver this aggregation also appeared to have been generated in part through asexual reproduction as 3 polyps shared the same multilocus genotype and were heterozygous at 5 loci (Table 1). The remaining 2 polyps sampled from aggregation $D$ had distinct genotypes, not shared by any other anemones assayed. In all cases the genotypes of polyps taken from these aggregations were electrophoretically distinct from those of visually distinct polyps collected from around their margins ( $n=26$; Table 1 ). We detected 2 multilocus genotypes within each of the 2 adjacent aggregations that displayed subtle colour variation (aggregations I and $\mathrm{J}_{\text {; }}$ 
Table 1. Anthothoe albocincta. Comparisons of colour and genotypic variability within sets of 5 polyps from each of 10 aggregations (A-J) at Flagstaff Hill, and genotypic variability within sets of 3 to 6 differently coloured polyps from areas adjacent to 6 of the aggregations. Numbers of polyps displaying each multilocus genotype are given in parentheses

\begin{tabular}{|c|c|c|c|}
\hline \multirow[t]{2}{*}{ Aggregation } & \multirow{2}{*}{$\begin{array}{l}\text { Colour pattern } \\
\text { (Oral disc/Tentacles) }\end{array}$} & \multicolumn{2}{|c|}{ No. of multi-locus genotypes (no. of polyps with each genotype) } \\
\hline & & Within aggregation & Within polyps adjacent to aggregations \\
\hline A & Orange/white & $1(5)$ & $2(2,1)$ \\
\hline $\mathrm{B}$ & Orange/green & $1(5)$ & $4(2,2,1,1)$ \\
\hline $\mathrm{C}$ & Orange/orange & $1(5)$ & $6(1,1,1,1,1,1)$ \\
\hline $\mathrm{D}$ & Orange/white & $3(3,1,1)$ & $3(1,1,1)$ \\
\hline$E$ & Orange/orange & $1(5)$ & $3(2,2,1)$ \\
\hline $\mathrm{F}$ & Orange-green/green-white & $1(5)$ & $2(2,1)$ \\
\hline G & Orange/white & $1(5)$ & Anemones \\
\hline $\mathrm{H}$ & Orange/orange & $1(5)$ & from close \\
\hline 1 & Orange-green/green-white & $2(3,2)$ & proximity \\
\hline $\mathrm{J}$ & Orange-green/green-white & $2(4,1)$ & cluster \\
\hline
\end{tabular}

Table 1). However, 1 multilocus genotype (heterozygous at 3 loci) was common to aggregations $I$ and $J$ ( 3 and 4 polyps, respectively) indicating that 3 clones were present within these 2 aggregations.

Although aggregations at Flagstaff Hill were typically both monomorphic and apparently monoclonal our surveys also revealed that some of the more common colour morphs occurred within at least several aggregations. For example, the most common genotype that we detected (heterozygous for 5 loci) was common to 2 of the sampled aggregations (D and $G$; Table 1) and polyps surrounding all the other well separated aggregations ( $A, B, C, E$ and $F$; Table 1). Moreover, this genotype displayed the most common phenotype (orange oral disc/white tentacles) that was distributed along the entire $23 \mathrm{~m}$ of rock wall examined. Similarly, the multilocus genotype (heterozygous for 4 loci) of the 2 genotypically identical anemones of aggregation I (Table 1) was the same as an individual surrounding aggregation $\mathrm{C}$ and the entire aggregation $\mathrm{F}$ (10 $\mathrm{m}$ away) all of which had an orange/green oral disc and green/white tentacles. These results are most easily explained by the close aggregation of identically coloured clones with movement of anemones within the population enabling clones to establish additional aggregations.

On the Mornington Peninsula jetty, there was no genotypic variation within 11 of the 12 pairs of anemones collected from aggregations (although 9 of the 11 aggregations were genotypically distinct). The sole exception was a pair of polyps of the most common orange/white colour morph that were separated by $2 \mathrm{~m}$ (the largest distance separating a pair of polyps taken from a single aggregation). However, some clones covered distances greater than $2 \mathrm{~m}$. For example, 2 aggregations of the same colour, separated by $3 \mathrm{~m}$ and with no differently coloured polyps in between, had the same multilocus genotype (heterozygous at 4 loci), whilst 2 polyps from an aggregation on one piling shared the multilocus genotype (heterozygous at three locil and colour as an anemone on an adjacent piling, a total separation of $5 \mathrm{~m}$. Combined, results from these 2 populations indicate that anemones from the same aggregation were electrophoretically identical in the majority of cases $(18 / 20)$.

\section{Genotypic diversity within populations}

Our assessment of the level and patterns of genotypic diversity present within all 13 populations implies that asexual reproduction plays the major role in all recruitment to these populations. Even though our estimates used only 1 polyp/aggregation we found that single-locus and multilocus genotype frequencies were always consistent with the predicted effects of asexual reproduction. We detected a high proportion of statistically significant departures from HardyWeinberg equilibria including 16 heterozygote excesses and 11 heterozygote deficits in a total of 66 tests $\left(\chi^{2}, p<0.05\right.$; Table 2$)$. Of the 13 populations, 5 exhibited both significant heterozygote excesses and deficits at different loci, and all populations were characterised by both heterozygote excesses and deficits (Table 2). Moreover, these surveys of 15 to 62 polyps per population all showed far fewer putative clones $\left(N_{\mathrm{g}}\right)$ than the sampled number of aggregations $(N) . N_{\mathrm{g}}$ ranged from 4 within the collection of 50 polyps from Merimbula to 27 in the collection of 50 polyps from Mornington (Table 3). Overall some 30 genotypes were shared by 5 or more individuals and in the extreme a single genotype at Flinders was shared by 30 widely separated polyps. Similarly, values of $G_{0}: G_{\mathrm{e}}$ were typically very low and ranged from 0.06 at Flinders to 0.49 at Tathra (Table 3 ). In all cases $G_{0}$ was highly statistically less than $G_{e}(p<0.005$; Table 3$)$ 
Table 2. Anthothoe albocincta. Departures from single-locus Hardy-Weinberg equilibria, given as Wright's (1978) $f$ values using the allele frequencies from groups of individual anemones. Positive values of $f$ reflect a deficit of heterozygotes, whilst negative values reflect an excess. N: sample size. Enzyme abbreviations are: GPI, glucosephosphate isomerase; PGM, phosphoglucomutase; IDH, isocitrate dehydrogenase; GDH, glutamate dehydrogenase; 6PGD, 6-phosphogluconate dehydrogenase; PEP-C, leucine-alanine peptidase; XDH, xanthine dehydrogenase. Dashes indicate fixation of 1 allele. Statistıcal significance of departures from expectations are indicated above each value as $p<0.05, \cdots p<0.01, \cdots p<0.001$. nd: not determined due to small expected value. na: IDH could not be scored for 3 populations

\begin{tabular}{|c|c|c|c|c|c|c|c|c|}
\hline \multirow[t]{2}{*}{ Population } & \multirow[t]{2}{*}{$N$} & \multicolumn{7}{|c|}{ Locus } \\
\hline & & Gpi-1 & Pgm-1 & $I d h-1$ & $G d h-1$ & $6 P g d-1$ & PepC-1 & $X d h-1$ \\
\hline Flagstaff Hill & 62 & $-0.348^{\circ}$ & $-0.225^{\circ}$ & $-0.440^{\circ}$ & -0.159 & +0.065 & $-0.451 \cdots$ & +0.034 \\
\hline Toothbrush Is. Nth & 50 & $-0.451 \cdots$ & +0.196 & - & $-0.031^{\text {nd }}$ & $+1.00 \cdots$ & - & -0.186 \\
\hline Toothbrush Is. Sth & 38 & $+0.722^{\circ}$ & $-0.298 \cdots$ & - & - & - & +0.221 & $-0.409^{\circ}$ \\
\hline Gravel Loader & 45 & $+0.524^{\cdots}$ & +0.021 & $-0.023^{\text {nd }}$ & -0.059 & $-0.011^{\text {nd }}$ & -0.134 & -0.071 \\
\hline Turtle Row & 50 & -0.099 & $+0.689 \cdots$ & $-0.351^{\circ}$ & -0.500 & $-1.00^{\text {nd }}$ & $+0.645 \cdots$ & +0.232 \\
\hline Bowen Is. & 44 & +0.162 & +0.023 & -0.075 & -0.062 & -0.125 & +0.285 & -0.081 \\
\hline Governor's Head & 23 & $+0.912 \cdots$ & +0.164 & - & $-0.045^{\text {nd }}$ & -0.394 & +0.151 & $-0.022^{\text {nd }}$ \\
\hline Ulladulla & 50 & -0.087 & -0.087 & - & - & $+0.695^{\cdots} \cdot$ & +0.096 & $-0.010^{\text {nd }}$ \\
\hline Tathra & 15 & - & $-0.481^{\circ}$ & $+0.841^{\cdots}$ & -0.429 & - & $-0.556^{\circ}$ & -0.304 \\
\hline Merimbula & 50 & $-0.020^{\text {nd }}$ & -0.081 & $+1.00 \cdots$ & - & - & - & - \\
\hline Flinders & 42 & $-0.704 \cdots$ & $+0.812 \cdots$ & na & $-0.953 \cdots$ & $-0.953 \cdots$ & $+0.876 \cdots$ & -0.063 \\
\hline Queenscliff & 49 & -0.289 & -0.169 & na & -0.167 & -0.155 & $-0.361^{.}$ & +0.191 \\
\hline Mornington & 50 & -0.147 & $-0.319^{\circ}$ & na & $-0.387^{\circ}$ & -0.235 & -0.262 & +0.287 \\
\hline
\end{tabular}

Table 3. Anthothoe albocincta. Estimates of the genotypic diversity of 13 southeastern populations. $N$ : number of individuals sampled $N_{\mathrm{g}}$ : number of unique multilocus genotypes detected; $G_{0}$ : observed multilocus genotypic diversity; $G_{e:}$ expected multilocus genotypic diversity, under the conditions of random mating and free recombination. Statistical significance of departures from $G_{0}: G_{e}=1$ given by $" p<0.005$ and $\cdots p<0.001$

\begin{tabular}{|lrrrrrl|}
\hline Population & $N$ & $N_{g}$ & $N_{\mathrm{g}}: N$ & $G_{0}$ & $G_{\mathrm{e}}$ & $G_{\mathrm{o}}: G_{\mathrm{e}}$ \\
\hline Flagstaff Hill & 62 & 19 & 0.17 & 7.4 & 54.2 & $0.14 \cdots$ \\
Toothbrush Is. (Nth) & 50 & 13 & 0.26 & 7.1 & 24.2 & $0.30 \cdots$ \\
Toothbrush Is. (Sth) & 38 & 11 & 0.29 & 3.2 & 19.5 & $0.16 \cdots$ \\
Gravel Loader & 45 & 18 & 0.40 & 8.1 & 17.0 & $0.48 \cdots$ \\
Turtle Row & 50 & 18 & 0.36 & 6.5 & 24.5 & $0.27 \cdots$ \\
Bowen Is. & 44 & 24 & 0.55 & 13.8 & 31.4 & $0.44 \cdots$ \\
Governor's Head & 23 & 12 & 0.52 & 5.2 & 13.5 & $0.39 \cdots$ \\
Ulladulla & 50 & 17 & 0.34 & 4.5 & 20.0 & $0.23 \cdots$ \\
Tathra & 15 & 9 & 0.60 & 6.4 & 13.2 & $0.49 \cdots$ \\
Merimbula & 50 & 4 & 0.08 & 2.1 & 4.9 & $0.43 \cdots$ \\
Flinders & 42 & 5 & 0.12 & 1.4 & 25.6 & $0.06 \cdots$ \\
Queenscliff & 49 & 16 & 0.33 & 6.7 & 381 & $0.18 \cdots$ \\
Mornington & 50 & 27 & 0.54 & 17.1 & 46.1 & $0.37 \cdots$ \\
Mean & 44 & 15 & 0.35 & 6.9 & 25.6 & 0.30 \\
\hline
\end{tabular}

indicating the greater importance of asexual reproduction in the formation, and not just expansion of aggregations within all populations.

The power of genetic data to distinguish between clones is dependent upon the number and variability of available polymorphisms. Here we detected between 3 and 7 loci polymorphic within each population (although IDH could not be scored for the 3 most south- ern populations). Plots of the number of variable loci used versus the number of putative clones (multilocus genotypes) detected were in most cases (8/13) not asymptotic with the number of genotypes detected, suggesting that we had not distinguished all genetically different clones within those samples (Fig. 2). Four plots that appeared to reach an asymptote [Flagstaff Hill, Toothbrush Island (South), Flinders and Mornington] along with 4 that appear to have failed to reach an asymptote (Bowen Island, Governor's Head, Tathra and Queenscliff) are shown in Fig. 2. Importantly, an asymptote was reached for the more intensively sampled Flagstaff Hill and Mornington populations (Fig. 2) indicating that all clones may have been identified in these collections.

\section{Monitoring of cleared quadrats}

Over all 3 populations $82 \%(1469 / 1790)$ of polyps reappearing in the cleared quadrats were the same colour pattern as those removed. At Flagstaff Hill and Port Kembla, 89\% (472/530) and 90\% (717/800) of polyps, respectively, were of the original colour and no temporal variation in colour morph recruitment was found $(F=1.02, \mathrm{df}=3, \mathrm{p}>0.05$ and $F=0.137, \mathrm{~d} f=2, \mathrm{p}>$ 0.05 , respectively). In contrast, at the Gutter, original coloured polyps accounted for only $61 \%$ (280/460) of the recruitment into patches and significantly more new colour morphs had recruited into this population in late May and July than in February and March ( $F=$ 3.45, $\mathrm{df}=3.24, \mathrm{p}<0.05$ ). 

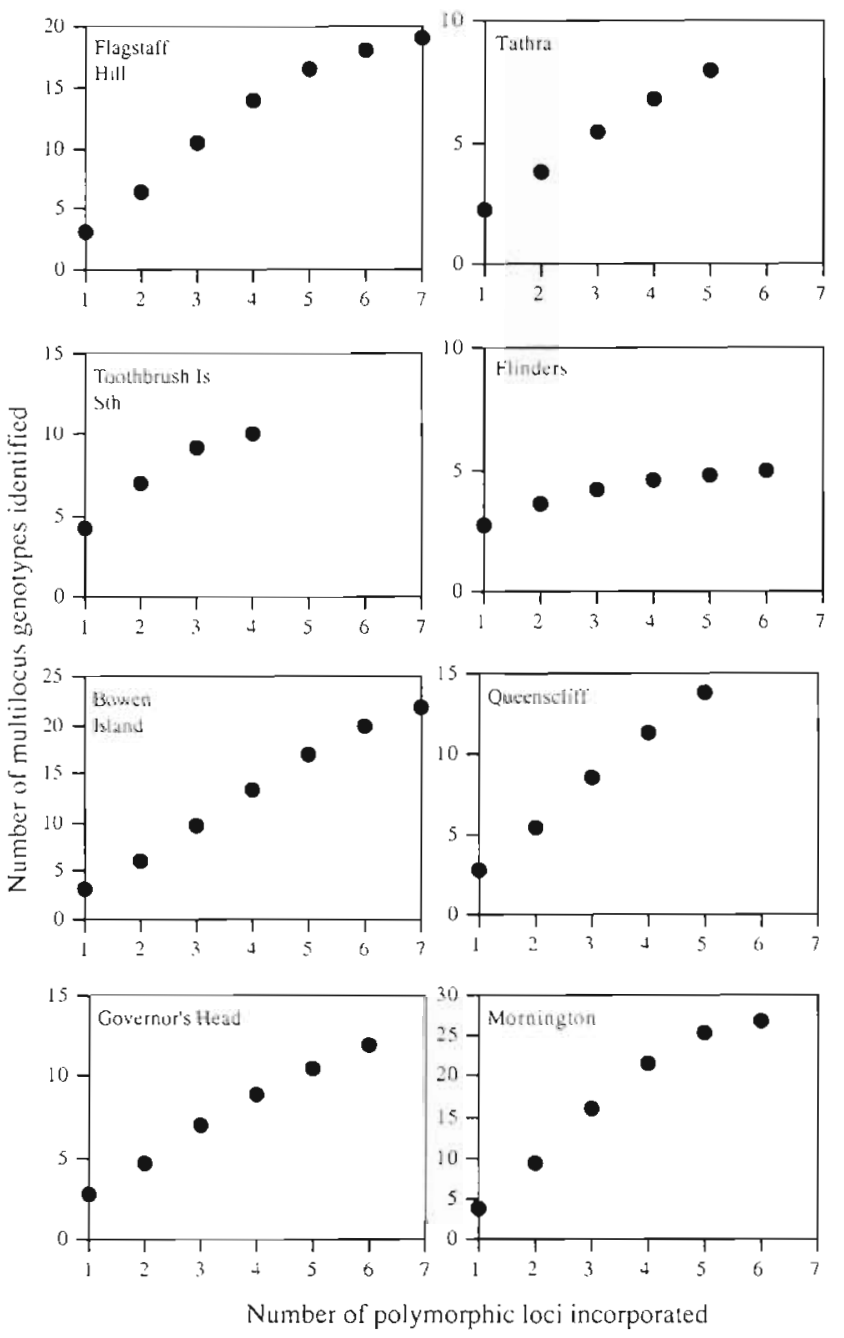

Fig. 2. Anthothoe albocincta. Plots of the number of unique multilocus genotypes identified versus the number of polymorphic allozyme loci employed in their detection, within 8 of 13 collections of anemones from southeastern Australian populations

\section{Laboratory observations}

We found that Anthothoe albocincta reproduces asexually in laboratory conditions. Fifty percent of polyps ( 9 of 18 ) maintained in aquaria for $16 \mathrm{wk}$ reproduced asexually via longitudinal fission. Each division produced a pair of viable and identically coloured polyps. Seven polyps divided on just 1 occasion and each produced 2 polyps of approximately equal size. The other 2 asexually reproductive individuals each gave rise to 4 anemones of equal size, although these divisions were not always symmetrical. Under these conditions fission scars were observed on all dividing anemones and persisted until the end of the observation period (up to $15 \mathrm{wk}$ ).

\section{DISCUSSION}

Comparative evidence for a wide range of terrestrial and freshwater taxa, with mixed modes of reproduction, suggests that sexual reproduction should be used whenever offspring are likely to encounter changed or uncertain conditions (Bonner 1958; see reviews by Williams 1975, Bell 1982). In the marine environment sexual reproduction is usually associated with the relatively uncertain process of planktonic dispersal and colonisation, whereas asexual reproduction may be used to restock the parental habitat patch (reviewed by Knowlton \& Jackson 1993, although see Stoddart 1988). Taken together our data imply that Anthothoe albocincta does use longitudinal fission as its primary means of replenishing established populations in southeastern Australia whereas sexual reproduction is used to produce colonising larvae. The resultant formation of clonal aggregations provides a simple proximate explanation for the observed spatial variation in polyp colour but contrasts with the prediction that such local populations should be replenished by sexually derived recruitment (Francis 1988). This population structure is similar to that reported for several intertidal sea anemones (e.g. Shick et al. 1979, Hoffmann 1986) including the sympatric intertidal species Actinia tenebrosa (Ayre et al. 1991).

\section{Asexual reproduction and the formation of monomorphic aggregations}

Although the genotypic structures of local populations provide the best indication of realised patterns of recruitment, our observations and simple experiments confirmed that Anthothoe albocincta can use asexual reproduction to generate pairs of similar sized individuals, with identical colour patterns. Surprisingly we found that, although basal laceration is usual within the Mesomyaria (Shick 1991), A. albocincta reproduced asexually through longitudinal fission. Longitudinal fission has however been reported in the congeneric South American, intertidal species A. chilensis and may be typical of this genus (Shick 1991). These observations alone are insufficient to indicate the relative importance of fission or any form of asexual reproduction for $A$. albocincta, however, fission is known to generate aggregations of genetically identical polyps in a range of species (Shick 1991).

Our fine-scale surveys of the genotypes of polyps from aggregations within 2 widely separated populations revealed that polyps collected from $90 \%$ (18 of 20) of monomorphic aggregations were genetically identical and were always electrophoretically distinct from neighbouring polyps with different colour patterns. 
These results strongly support the conclusion that aggregations are formed through fission and contrast sharply with the predicted effects of (1) outcrossed sexual reproduction, which should produce far greater genotypic diversity within aggregations, and (2) selffertilisation or close inbreeding, which should generate some genotypic variation within aggregations and low levels of heterozygosity. Although the functional significance of the array of colour morphs remains uncertain this variation therefore appears to represent a true genetic polymorphism (Lincoln et al. 1982). Similar, interclonal variation in colour patterns and pigments has been reported for the intertidal sea anemone Anthopleura elegantissima (Francis 1973) and the scleractinian coral Porites compressa (Hunter 1985)

For Anthothoe albocincta the importance of asexual reproduction does not seem limited to the expansion of single aggregations. Even though our surveys of most populations were designed to avoid resampling of aggregations (and so should underestimate the effects of localised fission) our resultant collections of genotypes were highly 'clonal', i.e. we detected both significant excesses and deficits of heterozygotes for each of 5 variable loci, and lower than expected multilocus genotypic diversity $\left(G_{0} \ll G_{e}\right)$ within all populations examined. Indeed, our resultant estimates of $G_{0}: G_{e}$ (mean $=30 \%$ ) for $A$. albocincta are amongst the lowest reported for marine invertebrates that use both sexual and asexual reproduction (e.g. Stoddart 1984, Johnson \& Threlfall 1987, Ayre \& Willis 1988, Mladenov \& Emson 1990, Ayre et al. 1991) and imply that individual clones frequently form multiple aggregations within sites. On average we detected only $15 \pm 2$ unique multilocus genotypes in our samples of $44 \pm 3$ polyps. Moreover, although we cannot be certain that it was represented by a single monomorphic clone, the most common multilocus genotype (with the same colour) was found along the entire $23 \mathrm{~m}$ of rockwall examined at the Flagstaff Hill and within some populations even rare colour morphs were seen to occupy vast areas of shore (Billingham \& Ayre unpubl. data).

\section{Sexual reproduction and recruitment}

The highly clonal nature of all of the surveyed populations of Anthothoe albocincta may mask the real importance of sexual reproduction for this species. Our observations of recruitment and our surveys of the genotypic diversity of adult populations imply that $A$. albocincta also recruits successfully through sexual reproduction. Moreover, if sexual reproduction is used to colonise new areas then both forms of reproduction should be equally important in the Iife-cycle of a successful lineage.
During this study most polyps colonising experimentally cleared patches at 3 sites displayed the same morphology as the original and surrounding residents of the quadrat. Such colonists were clearly the products of either current longitudinal fission or had simply walked from the remaining (non-cleared) portion of their aggregation. Nevertheless most Anthothoe albocincta polyps produced mature male or female gametes (Billingham \& Ayre 1996) and we detected recruitment by a high proportion of non-original colour morphs at the Gutter site in late May and July immediately after the March-April spawning peak (Billingham \& Ayre 1996). Many of these recruits displayed colour morphs not found in the vicinity of the quadrats. These data imply that we detected an episode of sexual recruitment at the Gutter site since recruits at the other 2 sites, and to the same Gutter quadrats during February and March, closely matched the morphology of surrounding polyps. Patchy or episodic recruitment has been detected or inferred for a number of anemones (Sebens 1982, Ayre 1984, Hoffmann 1987) and marine invertebrates in general (Loosanoff 1966, Fadlallah 1982, McFadden 1991, Menge 1991) and may in part reflect the potentially great longevity of individuals or clones.

Two additional forms of evidence support the premise of sexually derived recruitment in Anthothoe albocincta. First, we have shown previously (Billingham \& Ayre 1996) that this species is dioecious and with a high proportion of polyps reaching peak maturity just prior to the inferred recruitment episode at the Gutter site. Second, we have used a detailed analysis of genotypic and allelic variation among populations to infer that sexual reproduction is the primary source of colonists. Most significantly we found that although all populations contained multiple clones, clonal genotypes are not shared by neighbouring sites. Clonal propagules therefore seem unlikely to play a major role in the founding of new populations or in maintaining genotypic diversity within other established populations.

Acknowledgements. This work was supported by ARC grants to D.J.A. and the University of Wollongong's Department of Biological Sciences and Australian Flora and Fauna Research Centre. We thank Jeff Wright, David Skelly, Craig Styan, Anita Zubovic, Jim Sheehan, Sue Prutchard, Tanya Llorens, Rachel Standish, Nokome Bentley and Andy Davis for assistance with fieldwork and Sue Murray-Jones for comments on the manuscript. Publication no. 158 from the Ecology and Genetics Group of the University of Wollongong.

\section{LITERATURE CITED}

Ayre DJ (1983) The effects of asexual reproduction and intergenotypic aggression on the genotypic structure of populations of the sea anemone Actinia tenebrosa. Oecologia 57:158-165 
Ayre DJ (1984) The effects of sexual and asexual reproduction on geographic varation in the sea anemone Actinia tenebrosa. Oecologia 62:222-229

Ayre DJ (1985) Localised adaptation of clones of the sea anemone Actinia tenebrosa. Evolution 39:1250-1260

Ayre DJ (1995) Localised adaptation of sea anemone clones: evidence from transplantation over two spatial scales. J Anim Ecol 64:186-196

Ayre DJ, Dufty SL (1994) Evidence for restricted gene flow in the viviparous coral Senatopora hystrix on Australia's Great Barrier Reef. Evolution 48:1183-1201

Ayre DJ, Grosberg RK (1995) Aggression, habituation and clonal coexistence in the sea anemone Anthopleura elegantissima. Am Nat 146:427-453

Ayre DJ, Read J, Wishart J (1991) Genetic subdivision withın the eastern Australian population of the sea anemone Actunia tenebrosa. Mar Biol 109:379-390

Ayre DJ, Willis BL (1988) Population structure in the coral Pavona cactus: clonal genotypes show little phenotypic plasticity. Mar Biol 99:495-505

Behrens Yamada S (1989) Are direct developers more locally adapted than planktonic developers? Mar Biol 103: $403-411$

Bell G (1982) The masterpiece of nature: the evolution and genetics of sexuality. Croom Helm, London

Billingham MR, Ayre DJ (1996) Cienetic subdivision in the subtidal, clonal sea anemone Anthothoe albocincta. Mar Biol 125:153-163

Bonner JT (1958) The relation of spore formation in recombination. Am Nat 92:193-200

Bucklin A, Hedgecock. D. Hand C (1984) Genetic evidence of self-fertilization in the sea anemone Epiactis prolifera. Mar Biol 84:175-182

Burton RS (1986) Evolutionary consequences of restricted gene flow in the intertidal copepod Tigriopus californicus. Bull Mar Sci 39:526-535

Burton RS (1990) Hybrid breakdown in developmental time in the copepod Tigriopus californicus. Evolution 44: $1814-1822$

Carlgren O (1950) Actinaria and Zoantharia from South Australıa. K Fysiogr Sallsk 1 Lund Forh 20:121-135

Carlgren $O$ (1954) Actinaria and Zoantharia from South and West Australia. Ark Zool 6(34):571-584

Catmull J, Yellowlees D, Miller DJ (1987) NADP+ dependent glutamate dehydrogenase from Acropora formosa: purification and properties. Mar Biol 95:559-563

Fadlallah YH (1982) Reproductive ecology of the coral Astrangia lojollaensis; sexual and asexual patterns in a kelp forest. Oecologia 55:379-388

Francis L (1973) Clone specific segregation in the sea anemone Anthopleura elegantissima. Biol Bull 144:64-72

Francis L (1988) Cloning and aggression among sea anemones (Coelenterata: Actinaria) of the rocky shore. Biol Bull 174:241-253

Glantz SA, Slinter BK (1990) Primer of applied regression and analysis of variance. McGraw-Hill, New York

Grosberg RK (1987) Limited dispersal and proximity-dependent success in the colonial ascidian Botryllus schlosseri. Evolution 41:372-384

Grosberg RK (1991) Sperm-mediated gene flow and the genetic structure of a population of the ascidian Botryllus schlosseri. Evolution 45:130-142

Hedrick PW (1985) Genetics of populations. Jones and Bartlett Publishers, Boston

Hoffmann RJ (1986) Variation in contributions of asexual reproduction to the genetic structure of populations of the sea anemone Metridium senile. Evolution 40:357-365
Hoffmann RJ (1987) Short-term stability of genetic structure in populations of the sea anemone Metridium senile. Mar Biol 93:499-507

Hunt A, Ayre DJ (1989) Population structure in the sexually reproducing sea anemone Oulactss muscosa. Mar Biol 102 $537-544$

Hunter CL (1985) Assessment of clonal diversity and population structure of Pontes compressa (Cnidaria: Scleractinla). Proc 5th Int Coral Reef Congr 6:69-74

Johannesson K, Kautsky N, Tedengren M (1990) Genotypic and phenotypic differences between Baltic and North Sea populations of Mytilus edulis evaluated through reciprocal transplantations Il. Genetic variation. Mar Ecol Prog Ser 59:211-21.9

Johnson MS, Black R (1984a) The Wahlund effect and the geographical scale of variation in the intertidal limpet Siphonaria sp. Mar Biol 79:295-302

Johnson MS, Black R (1984b) Pattern beneath the chaos: the effect of recruitment on genetic patchiness in an intertidal limpet. Evolution 38:1371-1383

Johnson MS, Black R (1991) Genetic subdivision of the intertidal snail Bembicium vittatum (Gastropoda: Littorinidae) varies with habitat in the Houtman Abrolhos lslands, Western Australia. Heredity 67:205-213

Johnson MS. Threlfall TJ (1987) Fissiparity and population genetics of Coscinasterias calamaria. Mar Biol 93:517-525

Knowiton N, Jackson JBC (1983) Inbreeding and outbreeding in marine invertebrates. In: Thornhill NW (ed) The natural history of inbreeding and outbreeding: theoretical and empirical perspectives. The University of Chicago Press, Chicago, p 200-249

Lincoln RJ, Boxshall GA, Clark PF (1982) A dictionary of ecology, evolution and systematics. Cambridge University Press, Cambridge

Loosanoff VL (1966) Time and intensity of settling of the oyster, Crassostrea virginuca, in Long Island Sound. Biol Bull 130:211-227

McFadden CS (1991) A comparative demographic analysis of clonal reproduction in a temperate soft coral. Ecology 72 : $1849-1866$

McFadden CS, Grosberg RK, Cameron BB, Karlton DP, Secord DA (1997) Genetic relationships within and between solitary and clonal forms of the sea anemone Anthopleura elegantissima revisited: evidence for the existence of two species. Mar Biol 128:127-139

Menge BA (1991) Relative importance of recruitment and other causes of variation in rocky intertidal community structure. J Exp Mar Biol Ecol 146:69-100

Mladenov PV, Emson RH (1990) Genetic structure of populations of two closely related brittle stars with contrasting sexual and asexual life histones, wth observations on the genetic structure of a second asexual species. Mar Biol $104: 265-274$

Sebens KP (1982) Recruitment and habitat selection in the intertidal sea anemones Anthopleura elegantissuma (Brandt) and A. xanthogrammica (Brandt). J Exp Mar Biol Ecol 59:103-124

Selander RK, Smith MH, Yang SY, Johnson WB, Gentry JB (1971) Biochemical polymorphism and systematics in the genus Peromyscus. 1 Variation in the old-field mouse (Peromyscus polionotus). Stud Genet 6:49-90

Shaw PW (1991) Effects of asexual reproduction on popula tion structure of Sagartia elegans (Anthozoa: Actinaria). Hydrobiologia 216/217:519-525

Shick JM (1991) A functional biology of sea anemones. Chap man and Hall, London

Shick JM, Hoffmann RJ, Lamb AN (1979) Asexual reproduc- 
tion, population structure and genotype-environment interactions in sea anemones. Am Zool 19:699-713

Shick JM, Lamb AN (1977) Asexual reproduction and genetic population structure in the colonizing sea anemone Haliplanella luciae. Biol Bull 153:604-617

Stoddart JA (1984) Genelıcal structure within populations of the coral Pocillopora damicornis off southwestern Australia. Mar Biol 81:19-30

Stoddart JA (1988) Coral populations fringing islands: larval connections. Aust J Mar Freshwat Res 39:109-115

This article was presented by Roger Hughes (Senior Editorial Advisor), Bangor, Wales
Stoddart JA, Taylor JF (1988) Genotypic diversity: estimation and prediction. Genetics 118:705-711

Thomas IM, Shepherd SH (1982) Sea anemones. In: Shepherd SA, Thomas IM (eds) Marine invertebrates of Southern Australia. Part 1. Goverment Printer, South Australıa

Williams GC (1975) Sex and evolution. Princeton University Press, Princeton

Wright S (1978) Evolution and the genetics of populations, Vol 4. Variability within and among natural populations. University of Chicago Press, Chicago

Manuscript received: March 15, 1997

Revised version accepted: July 30, 1997 